\title{
Padrões de consumo de álcool e drogas em jovens torcedores de futebol
}

\author{
Anelise Lopes Rodrigues' \\ Jorge Castellá Sarriera \\ Universidade Federal do Rio Grande do Sul, Porto Alegre - RS - Brasil
}

\begin{abstract}
Resumo: O consumo de álcool e drogas entre jovens torcedores tem sido associado à violência no contexto do futebol. Este estudo buscou determinar os padrões de consumo das substâncias álcool, maconha e cocaína numa amostra de I.I30 torcedores de futebol residentes no Estado do Rio Grande do Sul, bem como verificar se existem diferenças relacionadas ao gênero, à faixa etária e ao pertencimento ou não a torcidas organizadas. A partir de um questionário disponibilizado na internet, os torcedores determinaram a frequência de consumo habitual e em dias de jogos de futebol. Adota-se metodologia quantitativa, e são realizadas análises descritivas, correlacionais e multivariadas dos dados. Os resultados apontam diferenças significativas nos padrões de consumo dos torcedores, sendo os homens na faixa etária de 23 a 25 anos, em dias de jogos, os que apresentam maior consumo. Verificam-se ainda diferenças significativas entre integrantes de torcidas organizadas e não integrantes.
\end{abstract}

Palavras-chave: álcool; drogas; adolescente; violência; futebol.

\section{PATTERNS OF ALCOHOL AND DRUGS CONSUMPTION IN YOUNG SOCCER FANS}

\begin{abstract}
Alcohol and drug consumption among young soccer fans have been associated with violence in soccer context. This study aims to determine patterns of alcohol, marijuana and cocaine consumption in a sample of I, I 30 soccer fans residents in the Rio Grande do Sul State, as well as to verify if there are differences regarding gender, age and if the participant is member of organized fan soccer or not. From a questionnaire available through Internet, soccer fan answered the frequency they generally consume these substances and in the days that there are soccer matches. Through the adoption of quantitative methodology, descriptive, correlational and multivariate analysis, data were performed. The results indicate the existence of differences in the consumption patterns of the investigated substances. Men aged between 23 to 25 years old presented significant higher means, as well as members of organized fan soccer for substances consumption.
\end{abstract}

Keywords: alcohol; drugs; adolescent; violence; soccer.

\section{PATRONES DE CONSUMO DE ALCOHOL Y DROGAS EN JÓVENES AFICIONADOS AL FÚTBOL}

Resumen: El consumo de alcohol y drogas entre los jóvenes hinchas de fútbol se ha asociado a la violencia en el contexto del fútbol. Este estudio trató de determinar los

1 Endereço para correspondência: Anelise Lopes Rodrigues, Instituto de Psicologia - Programa de Pós-Graduação em Psicologia, Rua Ramiro Barcelos, 2.600/122, Porto Alegre - RS - Brasil. CEP: 90035-003. E-mail: aneliselr@ hotmail.com. 
patrones de consumo de las sustancias de alcohol, marihuana y cocaína en una muestra de I.I 30 aficionados al fútbol residentes en el estado de Rio Grande do Sul, así como verificar si existen diferencias en el consumo según el género y grupo de edad, y que pertenecen o no a hinchadas organizadas. Desde un cuestionario disponible en la internet, los hinchas determinaron la frecuencia de consumo habitual y en días de partidos de fútbol. Se adopta la metodología cuantitativa y se llevan a cabo análisis descriptivos, correlacionales y multivariados de los datos. Los resultados muestran diferencias significativas en los patrones de consumo de los hinchas, con los hombres de 23 a 25 años e en el día del juego, los de mayor consumo. Se observan también diferencias significativas entre los miembros y no miembros de hinchadas organizadas.

Palabras clave: alcohol; drogas; adolescente; violencia, fútbol.

O uso de substâncias tem sido objeto de estudos nacionais e internacionais na área de saúde pública, em sua maioria associado a comportamentos de risco (Kuo, Yang, Soong, \& Chen, 2002; Ferigolo et al., 2004; Heim \& Andrade, 2008; Pechansky, Szobota, \& Scivolettob, 2004). No Brasil, o consumo elevado e precoce de álcool e drogas por jovens pode ser considerado uma epidemia silenciosa. De acordo com I Levantamento Domiciliar sobre o Uso de Drogas Psicotrópicas no Brasil, realizado pelo Centro Brasileiro de Informações sobre Drogas Psicotrópicas (Cebrid) em 2001 (Carlini, Galduróz, Noto, \& Nappo, 2002), a prevalência de uso de álcool ao menos uma vez na vida entre jovens de 12 a 17 anos foi estimada em 48,3\% da população. A Região Sul do Brasil registrou o maior índice de prevalência, estimado em 54,5\%. Já conforme os resultados do II Levantamento Nacional de Álcool e Drogas, realizado Instituto Nacional de Ciência e Tecnologia para Políticas Públicas do Álcool e Outras Drogas (Inpad) em 2012 (Laranjeira, 2014), considerando a população adulta (de 18 anos ou mais), houve um crescimento importante na experimentação precoce de bebidas alcoólicas, tanto no sexo masculino quanto no feminino. A proporção de homens que em 2006 declarou ter experimentado álcool com menos de 15 anos passou de $16 \%$ em 2006 para $24 \%$ em 2012. Entre as mulheres, a proporção aumentou de $8 \%$ para $17 \%$ no mesmo período. Considerando uma população estimada de cerca de 14 milhões de adolescentes brasileiros, a maconha foi a substância ilícita com maior prevalência entre jovens de 14 a 17 anos, e 4,3\% (correspondente a 600 mil jovens) relataram ter experimentado maconha ao menos uma vez na vida. Já a prevalência de uso da cocaína foi de 2,3\% (aproximadamente 316 mil jovens).

No que tange ao contexto específico do futebol, o consumo de bebidas alcoólicas por parte dos torcedores enquanto assistem às partidas tem sido um hábito historicamente associado à cultura futebolística no Brasil e no mundo. Entretanto, a conjunção entre álcool e futebol tem despertado a preocupação de autoridades de segurança pública, na medida em que uma terceira variável - a violência - tem sido parte integrante nessa associação. No Estado do Rio Grande do Sul, desde o mês de abril de 2008 , vigora lei que proíbe a comercialização e o consumo de bebidas alcoólicas nos estádios de futebol e nos ginásios esportivos como uma das medidas que visam prevenir manifestações violentas (Lei $n .12 .916,2008$ ). Em âmbito nacional, é a Confederação Brasileira de Futebol (CBF) que proíbe, por meio da Resolução n. 01 de 2008, o 
consumo e a venda de bebidas alcoólicas dentro dos estádios que sediam partidas de futebol integrantes de competições coordenadas pela entidade. Ainda que seja pacífica a ideia de que o álcool é um dos fatores associados à ocorrência de comportamento violento em torcedores de futebol, verifica-se - com base na literatura - certa mistificação em torno das relações existentes entre álcool, drogas, juventude e violência. Estudos atuais realizados pela Organização Mundial de Saúde na Europa apontam que substâncias como o álcool e outras drogas podem estar relacionadas à violência por meio de fatores de risco comuns, como em casos de transtornos de personalidade antissociais que contribuem tanto para o risco de abuso de álcool quanto para o comportamento violento. Nesses casos, o uso indevido de álcool e a violência interpessoal agiriam de modo cíclico, servindo de catalisadores um para o outro (World Health Organization, 2006). Estudo sobre representações sociais com adolescentes aponta que as principais representações positivas associadas ao consumo de bebida alcoólica são o prazer e a diversão, estando as representações negativas relacionadas à violência e à perda dos sentidos (Silva \& Padilha, 2013).

A despeito da preocupação das autoridades com a associação entre álcool, drogas e violência no contexto do futebol e ainda que a literatura venha reportando amplamente os riscos associados ao uso nocivo de álcool e drogas em espetáculos esportivos, evidencia-se escassez de estudos quantitativos que busquem determinar a prevalência e frequência de uso de álcool e drogas relacionados especificamente ao contexto do futebol. Em face disso, este estudo - de caráter descritivo e exploratório - tem por objetivo determinar os padrões de consumo de álcool e drogas em uma amostra de 1.130 torcedores de futebol residentes no Estado do Rio Grande do Sul. Especificamente, são analisadas diferenças no consumo segundo o gênero e faixa etária, assim como entre torcedores integrantes de torcidas organizadas e não integrantes. Compara-se ainda a frequência de consumo de álcool, maconha e cocaína realizada habitualmente pelos torcedores com a frequência de consumo realizada especificamente em dias de jogos de futebol.

\section{Método}

\section{Participantes}

Participaram deste estudo 1.130 torcedores de ambos os sexos (67\% do sexo masculino), com idades variando entre 15 e 25 anos ( $M=20,97$; $D P=3,10)$, todos residentes no Estado do Rio Grande do Sul. Destes, um total de 181 torcedores (correspondendo a $16 \%$ da amostra) relataram ser integrantes de torcidas organizadas de seus clubes. A média de idade no grupo dos torcedores integrantes de torcidas organizadas foi de 20,15 anos (DP = 3,17), e, no grupo de não integrantes, a média foi de 21,13 anos ( $D P=3,07$ ). Os participantes foram selecionados aleatoriamente pela internet. Para participação no estudo, adotaram-se os seguintes critérios: ter idade entre 15 e 25 anos, residir no Estado do Rio Grande do Sul e ser identificado como torcedor 
dos dois principais clubes de futebol do Estado: Grêmio Foot-Ball Porto Alegrense e Sport Club Internacional.

\section{Instrumentos}

Os torcedores responderam a duas escalas inspiradas no instrumento utilizado no I Levantamento Nacional sobre o Uso de Álcool, Tabaco e Outras Drogas entre Universitários (Andrade, Duarte, \& Oliveira, 2010), adaptadas para o uso específico relacionado ao contexto do futebol. As escalas buscaram dimensionar a frequência do uso das substâncias álcool, maconha e cocaína realizada habitualmente pelos torcedores, bem como a frequência de uso realizada mais especificamente em dias em que ocorrem jogos de futebol. Os participantes responderam, primeiramente, à seguinte questão: "Durante os últimos 12 meses, com que frequência você utilizou essa(s) substância(s)?". Em seguida, responderam à questão: "Durante os últimos 12 meses, em dias de jogos de futebol (antes, durante ou depois de assistir a jogos), com que frequência você utilizou essa(s) substância(s)?". A disposição dos itens se deu no formato Likert de 8 pontos, cujos valores variavam entre 0 , correspondente a "nunca", e 7 , correspondente a "diariamente ou quase sempre".

\section{Procedimentos de coleta e análise de dados}

Os torcedores foram convidados a responder à pesquisa, disponibilizada - em formato online - em um site criado especificamente para a realização do estudo. Por meio do recrutamento denominado opt-in (opção por entrar), foram disponibilizados convites via e-mail e nas redes sociais, comunidades e blogs temáticos relacionados aos clubes de futebol. Os convites virtuais continham um link que, ao ser clicado, encaminhava o participante diretamente à home page da pesquisa. No site da pesquisa, foram disponibilizados esclarecimentos sobre as características e os objetivos do estudo, bem como sobre os procedimentos éticos. Todos os participantes atestaram sua concordância em participar voluntariamente do estudo por meio do Termo de Consentimento Livre e Esclarecido, em formato on-line. Para os participantes menores de 18 anos, disponibilizou-se um link específico para atestar também o consentimento dos pais e/ ou responsáveis. O projeto que deu origem a este estudo foi aprovado pelo Comitê de Ética em Pesquisa envolvendo Seres Humanos da universidade de origem dos autores (Protocolo n. 2011025) e atende às normas estabelecidas pela Resolução n. 466/2012 do Conselho Nacional de Saúde. A fase de coleta dos dados ocorreu de dezembro de 2011 a abril de 2013.

A partir da base de dados, procedeu-se à análise dos resultados. Realizaram-se análises descritivas (obtenção de médias e desvios padrão) e inferenciais, visando à caracterização da amostra e à correlação de Pearson para verificar associação entre o consumo habitual das substâncias e o consumo realizado em dias de jogos. A fim de explorar diferenças para o consumo de substâncias em função do sexo e da faixa etária dos torcedores, realizaram-se análises Multivariadas de Variância (Manova) e de 
Variância (Anova). Também foi realizado teste $t$ para verificar se existiam diferenças entre as médias, considerando as variáveis sexo, faixa etária e pertencimento ou não pertencimento a torcidas organizadas. Os dados foram analisados por meio do programa estatístico SPSS (versão 18.0) e organizados em tabelas.

\section{Resultados}

Inicialmente, apresentam-se, na Tabela 1, os dados descritivos (porcentagens) referentes ao consumo habitual e em dias de jogos para as substâncias álcool, maconha e cocaína, considerando a amostra total ( $n=1.130)$.

\section{Tabela I. Frequência de consumo habitual e em dias de jogos para as substâncias álcool, maconha e cocaína $(n=I .130)$}

\begin{tabular}{lccccc} 
& Nunca & Quase nunca & Algumas vezes & Várias vezes & $\begin{array}{c}\text { Sempre ou } \\
\text { quase sempre }\end{array}$ \\
\hline Consumo habitual & & & & & \\
Álcool & $15,8 \%$ & $37,8 \%$ & $31,8 \%$ & $10,9 \%$ & $3,7 \%$ \\
Maconha & $82,2 \%$ & $10,6 \%$ & $3,8 \%$ & $1,9 \%$ & $1,4 \%$ \\
Cocaína & $96,3 \%$ & $1,9 \%$ & $1,3 \%$ & $0,5 \%$ & - \\
\hline Em dias de jogos & & & & & \\
Álcool & $35,1 \%$ & $23,7 \%$ & $15,9 \%$ & $12,4 \%$ & $12,8 \%$ \\
Maconha & $88,4 \%$ & $4,9 \%$ & $3,8 \%$ & $1,3 \%$ & $1,6 \%$ \\
Cocaína & $97,3 \%$ & $1,8 \%$ & $0,5 \%$ & - & $0,4 \%$ \\
\hline
\end{tabular}

Fonte: Elaborada pelos autores.

Com relação ao consumo habitual de álcool (considerando a soma dos que assinalaram as opções "nunca" ou "quase nunca" no questionário), a maioria dos torcedores $(53,6 \%)$ referiu baixo consumo de bebidas alcoólicas. Entretanto, $42,7 \%$ relataram beber algumas vezes ou várias vezes, e 3,7\% mencionaram que consomem sempre ou quase sempre. Em dias de jogos, observa-se um aumento no percentual de torcedores que relataram que nunca ou quase nunca consomem bebidas alcoólicas $(58,8 \%)$. Contudo, observa-se que o percentual daqueles que relataram beber sempre ou quase sempre aumentou para $12,8 \%$. Com relação ao consumo habitual de maconha, a ampla maioria relatou nunca haver consumido essa substância $(82,2 \%)$, e, em dias de jogos, o percentual foi ainda mais elevado $(88,4 \%)$ entre aqueles que relataram não consumir a substância. Dentre os que assumiram fazer uso habitual de maconha, $14,4 \%$ relataram que o fizerem quase nunca ou algumas vezes; $1,9 \%$, várias vezes; e 1,4\%, sempre ou quase sempre. Quanto ao consumo de cocaína, seja habitualmente 
$(96,3 \%)$ ou especificamente em dias de jogos de futebol $(97,3 \%)$, observa-se que a ampla maioria dos participantes do estudo relatou nunca haver consumido a substância.

Na Tabela 2, são apresentados os dados descritivos referentes ao consumo habitual e em dias de jogos para as substâncias álcool, maconha e cocaína, considerando a amostra total $(n=1.130)$. Apontam-se as médias, os desvios padrão e o resultado das correlações (valor p) para uso de álcool, maconha e cocaína, comparando o perfil de uso habitual das substâncias e o uso em dias de jogos.

Tabela 2. Correlação e comparação de médias para uso habitual e em dias de jogos das substâncias álcool, maconha e cocaína na amostra $(n=I .130)$

\begin{tabular}{lcccc} 
Substância & $\begin{array}{c}\text { Uso habitual } \\
\text { M (DP) }\end{array}$ & $\begin{array}{c}\text { Uso em dias de jogos } \\
\text { M (DP) }\end{array}$ & R Pearson & Valor $p$ \\
\hline Álcool & $2,49(1,86)$ & $2,48(2,55)$ & 0,736 & 0,00 I \\
Maconha* & $0,49(1,34)$ & $0,38(1,25)$ & 0,857 & 0,00 I \\
Cocaína & $0,09(0,54)$ & $0,07(0,59)$ & 0,775 & 0,00 I \\
\hline
\end{tabular}

* $p<0,05$ - diferença significativa entre as médias.

Fonte: Elaborada pelos autores.

Como se pode observar, a média referente à frequência de uso habitual de álcool $(2,49)$ é ligeiramente superior à média do uso de álcool em dias de jogos $(2,48)$, não havendo diferença estatisticamente significativa entre as duas médias $(t(1.129)=$ $0,189)$. Quanto à maconha, a média referente ao uso habitual da substância $(0,49)$ é superior à média do uso em dia de jogos $(0,38)$, com diferença estatisticamente significativa entre as duas médias $(t(1.129)=5,477 ; p<0,001)$. Já com relação à cocaína, a média do uso habitual $(0,09)$ mostra-se ligeiramente superior à média do uso em dia de jogos $(0,07)$, não havendo diferença estatisticamente significativa entre as médias $(t(1.129)=1,544 ; p=0,123)$. Os resultados da análise de correlação mostraram que todos os itens apresentaram relações significativas positivas entre si, e o uso de maconha apresentou forte correlação positiva significativa com o uso de maconha em dias de jogos de futebol $(r=0,857$; $p<0,01)$; o uso habitual de álcool apresentou forte correlação positiva significativa com o uso de álcool em dias de jogos de futebol $(r=$ 0,736; $p<0,01$ ); e, por fim, o uso de cocaína apresentou forte correlação significativa positiva com o uso dessa substância em dias de jogos de futebol $(r=0,775 ; p<0,01)$.

Na realização da Manova, consideraram-se como variáveis dependentes contínuas as médias do consumo (habitual e em dias de jogos) das substâncias álcool, maconha e cocaína, e como variáveis independentes o sexo e a faixa etária dos torcedores. A análise conjunta dessas variáveis revelou efeitos principais significativos em função do sexo $(p<0,001)$ e da idade $(p<0,001)$ dos torcedores, assim como apresentou diferenças significativas para a interação entre as variáveis sexo e idade $(p=0,035)$. Já os resultados da Anova permitem identificar as variáveis dependentes que contribuem 
para as diferenças por sexo e idade verificadas por meio da análise multivariada (Tabela 3). Observa-se que todas as variáveis contribuem para a diferença em função do sexo. Com base nisso, pode-se concluir que as médias do sexo masculino referentes à frequência de uso de álcool, maconha e cocaína (habitual e em dias de jogos) foram significativamente mais elevadas (no nível de significância de $p<0,001$ ) que as do sexo feminino.

\section{Tabela 3. Anova por idade e sexo para a amostra de torcedores}

\begin{tabular}{|c|c|c|c|c|c|c|}
\hline & Variável dependente & $\begin{array}{l}\text { Soma dos } \\
\text { quadrados }\end{array}$ & $g l$ & $\begin{array}{c}\text { Média } \\
\text { quadrada }\end{array}$ & $F$ & Sig. \\
\hline \multirow[t]{6}{*}{ Sexo } & Álcool uso habitual & 35,328 & 1 & 35,328 & 10,643 & 0,001 \\
\hline & Maconha uso habitual & 37,259 & 1 & 37,259 & 21,015 & 0,001 \\
\hline & Cocaína uso habitual & 3,392 & 1 & 3,392 & 11,657 & 0,001 \\
\hline & Álcool uso em dias de jogos & 273,536 & 1 & 273,536 & 44,971 & 0,001 \\
\hline & Maconha uso em dias de jogos & 25,596 & 1 & 25,596 & 16,653 & 0,001 \\
\hline & Cocaína uso em dias de jogos & 2,525 & 1 & 2,525 & 7,173 & 0,008 \\
\hline \multirow[t]{6}{*}{ Idade } & Álcool uso habitual & $|5|, 673$ & 2 & 75,836 & 22,847 & 0,001 \\
\hline & Maconha uso habitual & 8,444 & 2 & 4,222 & 20,381 & 0,093 \\
\hline & Cocaína uso habitual & 0,482 & 2 & 0,241 & 0,828 & 0,437 \\
\hline & Álcool uso em dias de jogos & 253,029 & 2 & 126,515 & 20,800 & 0,001 \\
\hline & Maconha uso em dias de jogos & 5,915 & 2 & 2,958 & 10,924 & 0,146 \\
\hline & Cocaína uso em dias de jogos & 0,728 & 2 & 0,364 & 10,034 & 0,356 \\
\hline \multirow[t]{6}{*}{ Sexo* Idade } & Álcool uso habitual & 13,322 & 2 & 6,661 & 2,007 & 0,135 \\
\hline & Maconha uso habitual & 9,033 & 2 & 4,516 & 2,547 & 0,079 \\
\hline & Cocaína uso habitual & 0,317 & 2 & 0,159 & 0,545 & 0,580 \\
\hline & Álcool uso em dias de jogos & 0,577 & 2 & 0,288 & 0,047 & 0,954 \\
\hline & Maconha uso em dias de jogos & 12,985 & 2 & 6,492 & 4,224 & 0,015 \\
\hline & Cocaína uso em dias de jogos & 0,728 & 2 & 0,364 & $\mathrm{I}, 034$ & 0,356 \\
\hline
\end{tabular}

$g l=$ Grau de liberdade; $F=$ F calculado; Sig. = Nível de significância.

Fonte: Adaptado do software SPSS versão I8.I.

No que tange à variável idade, verificou-se, a partir da análise de variância (Tabela 3), a existência de diferença significativa, já que os torcedores com idades entre 23 e 25 anos foram aqueles que apresentaram as médias significativamente mais elevadas $(p<0,001)$ em relação às demais faixas etárias para o uso do álcool realizado habitualmente $(M=2,89$; $D P=1,87)$ e também em dias de jogos $(M=3,35 ; D P=2,60)$. Foi 
verificado ainda efeito de interação significativo $(p<0,035)$ entre as variáveis sexo e idade para o uso de maconha em dias de jogos, e as médias dos sujeitos do sexo masculino entre 19 e 22 anos $(M=0,69$; $D P=1,65)$ contribuíram para essa diferença. Por fim, por meio da realização de teste $t$ para amostras independentes, compararam-se as médias referentes ao uso habitual de álcool, maconha e cocaína e o uso em dias de jogos de futebol no grupo de torcedores que integram torcidas organizadas $(n=181)$ e no grupo de não integrantes $(n=949)$.

\section{Tabela 4. Uso de substâncias entre integrantes de torcidas organizadas e não integrantes}

\begin{tabular}{lcccc} 
& $\begin{array}{c}\text { Não integrante de } \\
\text { torcida organizada } \\
\text { M (DP) }\end{array}$ & $\begin{array}{c}\text { Integrante de } \\
\text { torcida organizada } \\
\text { M (DP) }\end{array}$ & $t$ & $p$ \\
\hline Álcool uso habitual & $2,36(I, 79)$ & $3,16(2,06)$ & $-4,895$ & 0,001 \\
Maconha uso habitual & $0,4 I(I, 25)$ & $0,94(I, 68)$ & $-4,09$ I & 0,00 I \\
Cocaína uso habitual & $0,04(0,37)$ & $0,35(I, 01)$ & $-3,973$ & 0,00 I \\
Álcool uso em dias de jogos & $2,19(2,40)$ & $3,97(2,80)$ & $-7,994$ & 0,001 \\
Maconha uso em dias de jogos & $0,27(I, 14)$ & $0,93(I, 60)$ & $-5,232$ & 0,001 \\
Cocaína uso em dias de jogos & $0,02(0,29)$ & $0,35(I, 30)$ & $-3,418$ & 0,001 \\
\hline
\end{tabular}

Fonte: Elaborada pelos autores.

Por meio da realização do teste $t$ (Tabela 4), verificou-se que o grupo de torcedores integrantes de torcidas organizadas apresentou médias significativamente mais elevadas quando comparado ao grupo de não integrantes para o consumo das três substâncias investigadas (álcool, maconha e cocaína). Observa-se, no que tange à frequência de uso dessas substâncias, que a média mais elevada refere-se ao uso de álcool em dia de jogos no grupo de integrantes de torcidas organizadas, sendo essa média significativamente mais elevada quando comparada à média do grupo de não integrantes, com nível de significância associado de $p<0,001$. Constata-se ainda uma elevação na média referente ao uso de álcool em dias de jogos por parte do grupo de integrantes de torcidas organizadas quando comparada à média do próprio grupo relacionada à frequência de ingestão habitual de bebidas alcoólicas. Quanto ao uso de maconha em dias de jogos, os integrantes de torcidas organizadas apresentaram médias aproximadamente três vezes mais elevadas, quando comparadas ao grupo de não integrantes $(p<0,001)$, já que a média do uso habitual de maconha praticamente se mantém nesse grupo. No grupo dos não integrantes, verifica-se que a média do uso de maconha em dias de jogos é menor quando comparada à média de uso habitual da droga por parte desse grupo. Quanto ao uso de cocaína, percebe-se que novamente a média de uso habitual e em dias de jogos no grupo de torcedores organizados se 
mantém igual e, quando comparada ao grupo de não integrantes, é significativamente mais elevada, tanto no que se refere ao uso habitual quanto no uso em dias de jogos de futebol.

\section{Discussão}

Parcela significativa das pesquisas sobre consumo de drogas entre adolescentes e jovens adultos tem sido realizada em contextos escolares. Neste estudo, utilizou-se a pesquisa on-line como possibilidade metodológica no intuito de abranger - pela internet - uma amostra de jovens assumidamente torcedores de futebol para responder às questões sobre o consumo que fazem de álcool e outras drogas tanto no contexto relacionado ao futebol, quanto as relacionadas ao uso habitual. Para a compreensão das questões que levam ao uso de drogas, segundo Velho (2008), torna-se necessário compreender alguns códigos presentes em determinados contextos, bem como interpretar a rede de significados que envolvem grupos específicos dentro de determinado tempo histórico. Nesse caso, cabe-nos interpretar os códigos culturais presentes na sociedade brasileira, bem como aqueles que permeiam o universo do futebol, a fim de melhor compreender os padrões de consumo de álcool e drogas nessa amostra de jovens torcedores gaúchos.

Inicialmente, a fim de melhor analisarmos os resultados obtidos, é prudente considerarmos o contexto ampliado da juventude brasileira, cujos levantamentos nacionais sobre o uso de álcool e drogas entre jovens no Brasil (Carlini et al., 2002; Laranjeira, 2014) indicam alta prevalência de consumo de álcool e drogas por parte dessa parcela da população, conforme reportado anteriormente. O futebol, por sua vez, é considerado um símbolo dos valores culturais que melhor retrata o modo de ser dos brasileiros (Murad, 2012), e, para uma melhor compreensão e análise dos dados deste estudo, torna-se imprescindível considerarmos os aspectos culturais que cercam esse contexto. Sabe-se que o encontro entre amigos e o consumo de bebidas alcoólicas (seja dentro dos estádios ou fora deles) acabam sendo uma espécie de ritual associado aos hábitos de assistir aos jogos e torcer pelo time. Os resultados de nosso estudo sugerem a existência de diferenças na frequência de consumo de álcool de acordo com a faixa etária e o sexo, corroborando os resultados dos estudos citados e demonstrando que essas são variáveis importantes para determinar os padrões de consumo entre os jovens também no contexto que cerca o futebol. Os resultados sugerem ainda que o uso cotidiano de álcool, assim como de maconha e cocaína, por parte dos torcedores correlacionou-se significativamente com a frequência de uso também em dias de jogos de futebol, demonstrando que a parcela de torcedores que consome tais substâncias nos dias de jogos de futebol o faz também cotidianamente e não única e exclusivamente por ocasião dos jogos de futebol. Portanto, ainda que o consumo de bebidas alcoólicas seja um hábito historicamente associado à cultura futebolística, os resultados obtidos neste estudo, considerando a amostra total de torcedores, não evidenciaram aumento nos níveis de consumo das substâncias álcool, maconha ou cocaína relacionadas aos dias de jogos de futebol. 
É interessante observar que, contrário ao senso comum de que possa haver um maior consumo de substâncias (em especial de bebidas alcoólicas) em dias de jogos de futebol, os resultados obtidos com nossa amostra apontam que o consumo habitual de álcool e cocaína mostrou-se ligeiramente mais elevado do que aquele realizado em dias de jogos (Tabela 2). Compreende-se assim que o uso cotidiano dessas substâncias por parte dos torcedores (em festas ou usos ocasionais, por exemplo) difere pouco do uso realizado por ocasião de eventos futebolísticos. A média de uso cotidiano de maconha mostrou-se inclusive estatisticamente mais elevada do que a média de uso em dias de jogos. Considerando também as frequências (Tabela 1) relatadas pelos torcedores, observa-se que o percentual daqueles que relatam ter feito uso de álcool de modo habitual (ao menos uma vez na vida, em outras ocasiões sociais não relacionadas ao futebol) é maior do que daqueles que relatam tê-lo feito por ocasião de jogos de futebol.

Os resultados evidenciam, no entanto, peculiaridades e diferenças importantes quando se consideram o sexo e a faixa etária dos torcedores. Com relação à faixa etária, verificou-se, a partir da análise de variância (Tabela 3), que os torcedores com idades entre 23 e 25 anos foram aqueles que apresentaram as médias significativamente mais elevadas $(p<0,001)$ em relação às demais faixas etárias para o uso do álcool realizado habitualmente $(M=2,89 ; D P=1,87)$ e também em dias de jogos $(M=3,35$; $\mathrm{DP}=2,60$ ), corroborando levantamentos que apontam uma maior prevalência de uso de álcool conforme aumenta a faixa etária (Carlini et al., 2002; Centro Brasileiro de Informações sobre Drogas Psicotrópicas [Cebrid], 2006; Laranjeira, 2014). A fim de estabelecer algumas comparações entre os resultados obtidos neste estudo com aqueles obtidos em levantamentos populacionais (nacional e relativo à Região Sul do Brasil), cabe ressaltar que a amostra deste estudo abrange apenas jovens entre 15 e 25 anos. Considerando os levantamentos em nível nacional (Cebrid, 2006), a prevalência de uso na vida para jovens entre 18 e 24 anos foi de 48,4\%. Em nossa amostra, o percentual daqueles que assumiram ter feito uso de álcool ao menos uma vez durante a vida corresponde a $84,2 \%$ dos participantes, e apenas $15,8 \%$ relataram nunca ter feito uso dessa substância na vida. Em análises relacionadas especificamente a amostras da Região Sul do Brasil, a faixa etária que apresenta a maior dependência é a de 18 a 24 anos, seguida da de 25 a 34 anos, sendo a maconha e a cocaína as substâncias que apresentaram maior prevalência de uso na vida. A despeito das diferenças de abrangência de faixa etária deste estudo em relação ao levantamento referido, pode-se considerar que, em nossa amostra, é bastante elevado o índice de usuários de bebidas alcoólicas. Para a Região Sul do Brasil, os dados do mesmo levantamento (Cebrid, 2006) apontam para uma prevalência de uso de álcool na vida de $73,9 \%$, indicadores ainda inferiores aos encontrados em nossa amostra de torcedores. Com relação ao levantamento acerca do consumo de maconha no Brasil, estima-se que $8,8 \%$ já fizeram uso de maconha na vida, sendo $14,3 \%$ do sexo masculino e $5,1 \%$ do sexo feminino (Cebrid, 2006). Considerando apenas a Região Sul, a prevalência de consumo de 
maconha na vida foi de 9,7\%, e de cocaína, 3,1\%. Considerando os percentuais obtidos com nossa amostra de torcedores, o percentual referente ao uso de maconha ao menos uma vez corresponde a $17,7 \%$ da amostra e 3,7\% para o uso de cocaína, sendo os percentuais para ambas as substâncias moderadamente mais elevados.

Um dado preocupante e que não deve ser desconsiderado refere-se ao percentual de $25,2 \%$ dos torcedores que relataram consumir álcool várias vezes, sempre ou quase sempre em dias de jogos. Tal índice, de acordo com os padrões adotados em estudos de prevalência (Cebrid, 2006; Laranjeira, 2014), pode ser considerado como padrão de alto consumo e comportamento de dependência do álcool. No levantamento nacional referente à Região Sul do Brasil, estimou-se um índice de $17,4 \%$ de jovens dependentes de álcool, dos quais $24,2 \%$ eram do sexo masculino e $8,2 \%$ do sexo feminino (Cebrid, 2006). Logicamente, há que se considerar que o futebol, no contexto cultural brasileiro, é algo mais que um simples esporte, pois trata-se de um espetáculo de massas ao qual se agregam outros componentes que pouco ou nada têm a ver com o desenrolar da prática desportiva em si. Assim, o encontro com os amigos, o consumo de bebidas alcoólicas, o ambiente dos estádios são aspectos que historicamente fazem parte desse contexto. No entanto, ante os resultados obtidos em nosso estudo, observa-se que a recente promulgação de leis que proíbem a comercialização de bebidas alcoólicas nos estádios de futebol não tem sido suficiente para coibir o consumo excessivo de álcool pelos jovens torcedores nos dias de jogos. Uma espécie de efeito colateral importante provocado por essa proibição e que se faz evidente para quem frequenta tais contextos refere-se ao fato de que, uma vez proibido o consumo de bebidas alcoólicas no interior dos estádios, os torcedores têm realizado tal consumo na rua, em suas adjacências e muitas vezes momentos antes do adentrar os portões dos estádios (Rodrigues, 2014). Cabe salientar ainda que o consumo de bebida alcoólica no contexto do futebol costuma estar associado a representações positivas como prazer e diversão (Silva \& Padilha, 2013), as quais acabam por reforçar o uso e muitas vezes o abuso associado a esse contexto.

No que tange às diferenças verificadas em função da variável "sexo" para o uso das substâncias (Tabela 3), nosso estudo revelou padrão de consumo significativamente mais elevado de álcool, maconha e cocaína em sujeitos do sexo masculino, quando comparados ao sexo feminino. Tal achado tem sido amplamente reportado na literatura (Cebrid, 2006; Kuo et al., 2002; Pechansky et al., 2004), uma vez que sujeitos do sexo masculino têm apresentado maior uso na vida e maior dependência de álcool em todas as faixas etárias, quando comparados ao sexo feminino (a despeito do evidente aumento de consumo de álcool entre as mulheres, reportado em diferentes estudos). Também no que se refere ao uso de substâncias como maconha e cocaína (investigadas no presente estudo), em ambos os levantamentos - em nível nacional e referente ao Sul do Brasil -, o gênero masculino apresentou maior prevalência de uso na vida e maior dependência de álcool do que as mulheres, em todas as faixas etárias, sendo a maconha e a cocaína as substâncias que apresentaram maior prevalência de uso na vida. 
Outro achado que merece destaque diz respeito especificamente ao subgrupo de integrantes de torcidas organizadas (que representam 16\% da amostra). Constata-se, nessa parcela específica de torcedores, que há uma elevação nas médias de consumo de álcool em dias de jogos de futebol, quando comparadas ao consumo que esses torcedores fazem habitualmente. Verificou-se também uma maior prevalência (com diferença significativa) de uso de álcool, maconha e cocaína entre os integrantes de torcidas organizadas quando comparados aos não integrantes. Cabe ressaltar que as torcidas organizadas, conforme apontado por outros estudos (Murad, 2012; Reis, 2003), têm dinâmicas específicas de funcionamento que vão muito além da simples vinculação com um time de futebol. Além disso, a participação nesses grupos agrega outros componentes que pouco ou nada têm a ver com o desenrolar da prática de torcer pelo time, como consumo de bebidas alcoólicas e drogas ilegais, prática de atos de violência, entre outros fatores. Essa dinâmica específica relatada na literatura como espécie de códigos de conduta dos membros de torcidas organizadas ajuda, de certo modo, a compreender as médias significativamente mais elevadas no consumo de álcool, maconha e cocaína por parte dos integrantes de torcidas organizadas em nossa amostra, quando comparados aos não integrantes. Neste estudo, os índices elevados de uso de álcool e drogas por torcedores de futebol do Sul do país corroboram os dados fornecidos também pelo Juizado Especial Criminal (Jecrim-RS), onde, das 243 ocorrências registradas em partidas de futebol no ano de 2011, ao menos 170 foram referentes à posse de substância e entorpecentes (representando cerca de $70 \%$ dos incidentes), sendo os demais $30 \%$ divididos entre brigas e discussões entre torcedores e outros delitos (Tribunal de Justiça do Rio Grande do Sul, 2011).

\section{Considerações finais}

Os objetivos do presente estudo foram determinar os padrões de consumo de álcool e drogas em uma amostra de torcedores de futebol e analisar diferenças referentes a esse consumo com base em critérios como o sexo e a faixa etária dos sujeitos, bem como o pertencimento ou não pertencimento em torcidas organizadas. Cabe, por fim, reafirmar o caráter analítico-descritivo adotado neste estudo e assumir as limitações inerentes ao método. Para tanto, salienta-se que a determinação dos padrões de consumo de álcool e drogas nessa amostra de jovens torcedores não é passível de associação com quaisquer fatores de risco, uma vez que haveria a necessidade de estabelecer uma diferenciação entre o uso recreativo ou ocasional dessas substâncias e o abuso (ou dependência). Há que se considerar também a necessidade de distinção entre drogas consideradas legais (como o álcool) e as drogas ilegais (maconha e cocaína). Referimos igualmente como limitações do estudo o fato de a amostra caracterizar-se como de conveniência, com dados não randomizados e cujos participantes são apenas pessoas que tiveram acesso à internet, bem como o fato de o questionário não ter dados de validação, sendo as quantidades de consumo passíveis de diferentes interpretações por parte dos participantes. Sugerem-se, para investigações futuras, estudos qualitativos e 
epidemiológicos que permitam uma melhor compreensão dos efeitos do uso de álcool e demais substâncias como precipitantes de situações de violência no contexto do futebol.

\section{Referências}

Andrade, A. G., Duarte, P. C. A. V., \& Oliveira, L. G. D. (2010). I Levantamento Nacional sobre o Uso de Álcool, Tabaco e Outras Drogas entre Universitários das 27 Capitais Brasileiras. Brasília: Secretaria Nacional de Políticas sobre Drogas.

Carlini, E. A., Galduróz, J. C. F., Noto, A. R., \& Nappo, S. A. (2002). I Levantamento Domiciliar sobre o Uso de Drogas Psicotrópicas no Brasil: estudo envolvendo as 107 maiores cidades do país. São Paulo: Cebrid, Unifesp.

Centro Brasileiro de Informações sobre Drogas Psicotrópicas (2006). II Levantamento Nacional sobre o Uso de Drogas Psicotrópicas no Brasil: estudo envolvendo as 108 maiores cidades do país. São Paulo: Cebrid.

Ferigolo, M., Barbosa, F. S., Arbo, E., Malysz, A. S., Stein, A. T., \& Barros, H. M. T. (2004). Drug prevalence at Febem, Porto Alegre. Revista Brasileira de Psiquiatria, 26(1), 9-15.

Heim J., \& Andrade, A. G. (2008). Efeitos do uso do álcool e das drogas ilícitas no comportamento de adolescentes de risco: uma revisão das publicações científicas entre 1997 e 2007. Revista de Psiquiatria Clínica, 35(1), 61-64.

Kuo, P. H., Yang, H. J., Soong, W. T., \& Chen, W. J. (2002). Substance use among adolescents in Taiwan: associated personality traits, incompetence, and behavioral/emotional problems. Drug and Alcohol Dependence, 67, 27-39.

Laranjeira, R. (2014). II Levantamento Nacional de Álcool e Drogas (Lenad). O consumo de álcool no Brasil: tendências entre 2006 e 2012. Inpad. Relatório 2012. São Paulo: Unifesp.

Lei n. 12.916, de $1^{\circ}$ de abril de 2008 (2008). Dispõe sobre a proibição da comercialização e o consumo de bebidas alcoólicas nos estádios de futebol e nos ginásios de esportes do Estado do Rio Grande do Sul. Porto Alegre. Recuperado em 12 julho, 2012, de http://www.mp.rs.gov.br/infancia/legislacao/id3837.htm.

Minayo, M. C. S. (1994). Social violence from a public health perspective. Caderno de Saúde Pública, 10(1), 7-18.

Murad, M. (2012). A violência no futebol. São Paulo: Saraiva.

Pechansky, F., Szobota, C. M., \& Scivolettob, S. (2004). Uso de álcool entre adolescentes: conceitos, características epidemiológicas e fatores etiopatogênicos. $R e-$ vista Brasileira de Psiquiatria, 26(supl. I), 14-17. 
Reis, H. H. B. (2003). Os espectadores de futebol e a problemática da violência relacionada à organização do espetáculo futebolístico. Revista Paulista de Educação Física, 17(2), 85-92.

Resolução da Presidência n. 01, de 29 de abril de 2008 (2008). Rio de Janeiro: Confederação Brasileira de Futebol. Recuperado em 15 junho, 2012, de http://listas. cev.org.br/cevleis/2008-June/034024.htm.

Rodrigues, A. L. (2014). Violência entre torcedores de futebol: prevalência de comportamento violento e variáveis psicossociais associadas. Tese de doutorado, Universidade Federal do Rio Grande do Sul, Porto Alegre, RS, Brasil.

Silva, S. É. D. da, \& Padilha, M. I. (2013). O alcoolismo na história de vida de adolescentes: uma análise à luz das representações sociais. Texto \& Contexto Enfermagem, 22(3), 576-584.

Tribunal de Justiça do Rio Grande do Sul (2011). Jecrim nos estádios: balanço da atuação em 2011. Recuperado em 17 julho, 2012, de http://www.acriergs.com.br/ noticia-11-jecrim-nos-estadios-balanco-atuacao-em-2011.

Velho, G (2008). Nobres e anjos: um estudo de tóxicos e hierarquia. Rio de Janeiro: FGV.

World Health Organization (2006). Interpersonal violence and alcohol: WHO policy briefing. Geneva: WHO.

Submissão: $23 \cdot 10.2015$

Aceitação: 10.8 .2015 